\title{
Factors leading to increased operational costs in a public hospital in São Paulo, Brazil
}

Janaína Monique Ferreira de Souza ( $\sim$ janainamfsouza@gmail.com )

Hospital Israelita Albert Einstein https://orcid.org/0000-0002-3900-2359

Adriano J Pereira

Hospital Municipal Vila Santa Catarina

Eliezer Silva

Hospital Israelita Albert Einstein

\section{Research article}

Keywords: cost analysis, hospital operational costs, cost factors in hospital administration

Posted Date: December 2nd, 2019

DOI: https://doi.org/10.21203/rs.2.17946/v1

License: (c) (i) This work is licensed under a Creative Commons Attribution 4.0 International License. Read Full License

Version of Record: A version of this preprint was published at Jornal Brasileiro de Economia da Saúde on December 1st, 2020. See the published version at https://doi.org/10.21115/JBES.v12.n3.p206-12. 


\section{Abstract}

Objectives - To quantify the operational costs of a municipal public hospital in the city of São Paulo (Brazil) and to identify factors that led to cost increases during the year of 2016 using the absorption method.

Method - This was a retrospective study conducted between January and December of 2016 at Vila Santa Catarina Municipal Hospital, a public tertiary hospital in São Paulo, Brazil.

Results - We identified and analyzed a total of 8702 inpatient data. Average day cost per patient was US\$ 949 , with a median of US\$ 1,825 , and a total operating cost of US $\$ 48,743,847$. Transplant patients showed the highest median costs, while pregnant women had the lowest median costs. The cost for $6083(69.9 \%)$ of the 8702 hospitalized patients was above the mean cost of US\$3,068 registered for 2016 . Age was associated with a $6.6 \%$ increase in cost for each one-year increase in age, while the cost associated with female patients was 1.1 times that of men. Patients who died in the hospital were 8 times more likely to cost more than patients who were discharged from the hospital. Oncology, transplant, and clinical-surgical patients had 18.8 times ( $p<0.001)$, 15.8 times $(p<0.001)$ and 13.7 times $(p<0.001)$ the cost of patients in the maternity unit, respectively.

Conclusion - We identify the operating costs of the Vila Santa Catarina Municipal Hospital, where the average cost for the operation of the unit was US\$ 133.179. The cost per patient was US\$ $1,825.91$. We also concluded as to the second objective that the cost increase factors were age and death.

\section{Background}

According to the World Health Organization (WHO), about 9\% of Brazilian GDP is allocated to the health sector, which is considerably lower than that allocated by the United States $(17.1 \%)$ or Canada (10.4\%). Although like the GDP percentage allocated by the United Kingdom (9.1\%), the per capita values allocated by these two countries differ significantly (UK: US\$ 3,377 vs. Brazil: US\$ 1,318). Furthermore, health services in Brazil do not meet the required efficiency standards.[1,2]

In Brazil, there are very few reports on the use of costing systems in hospitals belonging to the public health system (Sistema Único de Sáude- SUS). However, reports indicate that the most frequently used system is the macro-accounting method.[3-7] Studies published since 2009 report a growing concern with this scenario, as they suggest that the macro-accounting method can significantly distort the cost calculation (costs per department or procedure) by allowing or even indirectly encouraging cost variations and alterations among providers of the same service. In a country marked by budgetary and financial constraints, these distortions may result in unequal resource allocations, thus directly affecting the health system's universality and integrity.[8,9]

In view of these problems, private institutions have begun to look for improved health financing models. Since 2014, Hospital Israelita Albert Einstein (HIAE), a private hospital in São Paulo, has adopted Triple Aim governance, an innovative program that has changed the approach, structuring and monitoring of health services while focusing on care and reducing per capita health service costs.[10] Hospital Municipal Vila Santa Catarina (HMVSC), a public hospital in São Paulo (Brazil), was inaugurated in July 2015 with a total of 170 beds and a budget of US\$ 50.1 million through a public/private partnership between HIAE and the Brazilian Ministry of Health. This partnership was established as part of a program called "Programa de Apoio so Desenvolvimento Institucional ao SUS" (Program for Institutional Development of the Unified Health System).

Thus, the aim of the present study was to quantify the operational costs of a municipal public hospital in the city of São Paulo (Brazil) and to identify factors that led to cost increases during the year of 2016.

\section{Methods Study design}

The study was conducted from January to December 2016. Results from this retrospective study are reported following the Consolidated Health Economic Evaluation Reporting Standards (CHEERS) checklist.[11]

Data were obtained from Hospital Municipal Vila Santa Catarina's (HMVSC) hospital management system (Sistema de Gerenciamento Hospitalar, SGH). From this system, we selected all inpatients in the medical-surgical, maternity, oncology and transplant units. HIAE accounting department calculated all costs and cost drivers, obtaining the average cost per patient at the end of each month. All direct and indirect costs were measured by each department cost center and were extracted from the accounting sector database. With the exception of materials and drugs (for which real costs were calculated) all other costs were calculated using the absorption method Costs data were obtained in Brazilian currency (R\$ - real) and converted to United States dollars (US\$) using currency converter from Central Bank of Brazil.[12,13] Costs were calculated in the local currency (Brazilian Reais) and converted to USD at the rate of 3.26 BRL to 1 USD on December $30^{\text {th }}, 2016$.

The All Patients DRG (Diagnosis Related Group) system was used to group patients according to Major Diagnostic Categories (MDC). A Business Intelligence (BI) platform was used to integrate data from the different systems (SGH, DRG and cost databases), sobered in a Data Warehouse - DW (SQL) and using the QlikView visualization tool (Qlikview®, Radnor, PA, EUA).

We conducted statistical testing to determine whether cost increase was associated only with length of hospital stay or with other variables as well. Data extracted from the database were transferred to an Excel spreadsheet to calculate costs per patient, lengths of stay (LOS) and the factors associated with increased costs. 


\section{Baseline measurements}

From January 1 to December 31, 2016, there were 9,818 admissions corresponding to 8,702 patients. Our three set of data were analyzed, as follows: (1) clinical data (age, sex, race, length of stay, outcome hospital discharge); (2) type of MDC; and (3) cost drivers (Daily, Procedures [Blood Bank and Hemodynamics], surgical center, multiprofessional, dialysis, medical exams and honorariums).

We used the cost-efficiency model in R (R Core Team, 2016), version 3.4.1, and SPSS (IBM SPSS Statistics for Windows, Version 24.0) to identify factors leading to cost increases.

Patient operational and total costs, as well as hospitalization, are shown as percentages.

Mean costs are shown as histograms or boxplots, together with standard deviation (SD), minimum and maximum limits, medians (MED) and quartiles.

Categorical variables are described as absolute frequencies and percentages, and quantitative variables are described as medians and quartiles. Structured Equation Modeling (SEM) was adjusted to investigate associations among variables within and between departments; this provided a simple approach to verify the dependence among a single patient's hospitalizations during the study period. Results are presented as odds ratios (RC) and $95 \%$ confidence intervals. The high cost and not high cost groups were compared relative to length of stay and costs by non-parametric Mann-Whitney tests, considering a significance level of $5 \%$.

\section{ETHICAL CONSIDERATIONS}

The Research Ethics Committee of the HIAE and the Ethics Committee of the Municipal Health Department of the city of São Paulo approved and registered the study under number CAAE 55094716.2.0000.0071.

\section{Results}

The total number of patients included in this study was 8,702, with a total of 9,602 hospitalizations (see Table 1). During 2016 , only $6.7 \%$ of patients were hospitalized more than once. The death rate was $2.7 \%$. The median length of hospital stay was three days and the third quartile were four days, indicating the predominance of shorter hospitalizations 2.95 days $[2.35 ; 4.22]$.

\section{Costs per patient}

The median cost per patient was US\$ 1,825.91 (Table 1). The average operational cost per day was US\$133,179. Considering only fixed costs, the amount required to keep the hospital operating with its 1,052 employees and an average occupancy rate of $53.49 \%$ was US\$ 377,280 per day.

Patients $0-18$ years old made up $41.78 \%$ of admissions and had an individual monthly cost of US\$197, while patients 59 or older (11.87\% of patients) cost approximately 5.81 times as much, at US\$1,441/month. Monthly individual hospitalization costs rose linearly among patients 34 and older. Interestingly, mean costs per patient in the 49-53 and 54-58 age brackets were even higher than those for the $59+$ group, but those patients comprised only a small percentage (around $2-2.5 \%$ ) of hospitalizations.

The overall average hospitalization cost in 2016 was US $\$ 1,891 /$ day, but the mean was skewed by a single patient whose 170-day hospitalization cost was US\$ 613,666 . In fact, $90.1 \%$ of all patients hospitalized in 2016 had costs below the mean of US\$18,409. While $69.9 \%$ of patients had daily hospitalization costs below US\$3,068 (19\% of total HMVSC hospitalization costs), only $5.22 \%$ of patients had costs exceeding US\$18,409 (47.31\% of the total cost).

The highest average hospitalization costs were those reported for the transplant unit (US\$ 17,708), whereas the maternity unit had the lowest average costs (US\$1,987). The Medical-Surgical and Medical Clinic Departments were the most cost-efficient, with $36 \%$ and $35 \%$ of total hospital costs, respectively.

The average hospitalization cost for the 236 patients who died in the hospital was much higher (US\$23,861) than the average cost of the 9,366 patients who were discharged after variable hospitalization periods (US\$ 4,603).

\section{Hospitalization Costs relative to Major Diagnostic Categories}

A total of 204 Diagnosis Related Groups (DRG) were identified, and a clustering analysis was conducted using Major Diagnostic Categories (MDC). The highest average costs (US\$69,358) were recorded for three patients from the "alcohol/drug use and alcohol/drug induced organic mental disorders" group with three hospitalizations each during 2016 (cf. Table 2), and the second highest average cost was found for nine patients in the HIV group.

The department showing the lowest costs was the maternity unit, which had relatively shorter length of stay and a lower use of expensive materials and medications. The main cost driver for this unit was the use of the obstetrical center.

\section{Factors leading to increased operational costs}

In terms of length of stay and Cost Drivers $(C D)$ in the high-cost group, hypothesis testing showed that groups differed in terms of length of stay ( $<<0.001)$ and CDs 
$(p<0.001)$, (cf. Table 3 and 4).

Costs increased $6.6 \%$ for every one-year increase in age. Also, female patients presented an estimated odds ratio of 1.1 times the men's chance of increasing the cost

$(p=0.013)$. Relative to patients who were identified as brown, white patients had 1.4 times

$(p<0.001)$, Asian patients had 1.7 times $(p=0.078)$, and black patients had 1.7 times the chance of high cost hospitalizations $(p=0.672)$. In terms of lower costs, maternity unit, the oncology, transplant and medical-surgical clinics had estimated odds of $18.8,15.8$, and 13.7 times the median cost, respectively ( $p$ $<0.001$ ). When analyzed by MDC, "Newborns and other neonates with perinatal conditions" had significantly lower chances of increasing costs ( $<<0.001$ ) relative to all other patient groups, presenting the lowest proportion of high-cost hospitalizations. Finally, patients who died during 2016 had eight times the chance of increasing costs compared to patients who were discharged $(p<0.001)$.

Among the Major Diagnostic Categories, "Diseases and disorders of the male reproductive system" stood out as the major influence of cost increases.

\section{Discussion}

In this first of its kind study, we introduced in a public hospital in a Brazil a system used in the private sector to analyze resources and cost management. The total operational costs at HMVSC in 2016 were US\$ 48.7 million (within the initially proposed budget of approximately US\$ 50.1 million). Overall, the factors that determined heightened hospital costs were age, disease severity and medical procedure complexity.

As stressed by Kaplan and Porter [14], understanding hospitalization profiles allows for a better allocation of increasingly finite resources.

Given the financial restraints experienced in any current health care system in the world, such understanding is critical for resource planning and allocation. In its first year of operation, the HMVSC admitted oncology and transplant patients, which are mostly in the high cost group, since in this study we calculated costs associated with hospitalization pre-, during and post-transplantation, and did not consider consultation and outpatient care costs.

A study conducted in Ontario, Canada, also labeled oncology patients as non-high cost group, reporting operational costs in the diagnostic investigation of outpatients with breast cancer.[15] Omachonu et al. (2004) examined how patient characteristics and clinical indicators affected the length of stay for key DRG-related groups of Medicare patients in a teaching hospital in the United States. Using mathematical models, they found that age is associated with an increase in length of stay (LOS) for psychiatric DRGs and that men had longer LOS for three DRG-related conditions: heart failure and shock, psychiatric disorders, and rehabilitation. In our study, longer LOS increased costs in the high cost group (median: 3.9 days). In terms of age, each additional year was associated with up to $6.6 \%$ higher operating costs, consistent with Dormont et al. (2007).[16] However, unlike this last study, women and men in our study were equally represented in the higher cost group.[17]

Ferraz et al [18] found that expenditures progressively increase over the four years prior to a patient's death. The highest average cost in our study was for patients who died during 2016. Thus, in line with Koenig et. al. [18,19], severely ill patients in our study resulted in higher relative costs.

In 2015, Sacks et al. showed that excess alcohol consumption represents $76.7 \%$ of health care costs, with an average government cost of US\$ 3.5 billion per US state [18]. In line with these findings, in our cohort, the highest average cost in the MDC "alcohol/drug use and alcohol drug induced organic mental disorders" group came from three patients who were awaiting an organ in the transplant unit.

Although here we only aimed to measure costs and to identify factors that increase them, we must recognize that the success of this model also depends on identifying the direct cost of labor per health care professional, an approach that employs the micro count methodology, which we intend to use in future studies.[14]

The average length of stay of the DRG tool can be used to calculate outcome costs. This cost model remains controversial until fully evaluated, but it allowed us to verify the profile of hospitalizations, which followed HMVSC's intended criteria.

This work was the first to use the DRG system as a discharge diagnosis in a municipal public hospital, which would normally use the ICD (International Classification of Diseases; employed by the SUS for such purposes). The goal is to enable health policy makers to develop meaningful comparisons of the relative performance of hospitals in terms of efficiency and quality.[16]

\section{Conclusions}

We identify the operating costs of the Vila Santa Catarina Municipal Hospital, where the average cost for the operation of the unit was US\$ 133.179. The cost per patient was US\$1,825.91. We also concluded as to the second objective that the cost increase factors were age and death.

Similar cost-efficiency studies should be performed in other public hospitals in Brazil to compare and quantify costs across several institutions. These studies are urgent to support needed changes in the present hospital financing model of the Brazilian public health system. Identifying factors leading to increased operating costs will allow, over time, to establish budget targets appropriate for individual hospital admissions profiles.

\section{Declarations}

\section{Competing Interests}


None of the researchers has any conflict of interest.

\section{Funding}

This study only was possible thanks to the partnership with the Brazilian Ministry of Health, with resources from the PROADI-SUS (according to the Federal Act $n^{\circ} 12.101$, de 2009). The general aim of the program is to transfer expertise from institutions with excellent management and health care practices to units of the public health system.

\section{Acknowledgments}

We would like to acknowledge Guilherme de Paula Pinto Schettino, MD, Gabriela Sato, RN, and all the professionals from each of the HMVSC services who contributed to developing this study.

\section{References}

1. WHO | Brazil. WHO [Internet]. World Health Organization; 2017 [cited 2017 Nov 2]; Available from: http://www.who.int/countries/bra/en/

2. Porter ME. What Is Value in Health Care? N Engl J Med [Internet]. 2010;363:2477-81. Available from: http://www.nejm.org/doi/abs/10.1056/NEJMp1002530

3. Frank WG. A Managerial Accounting Analysis of Hospital Costs. Health Serv Res. 1976;34-44.

4. Gomes Y, Azevedo P, Gomes AM. INVESTIGAÇÃO DOS MÉTODOS DE CUSTEIO UTILIZADOS PELOS HOSPITAIS PÚBLICOS DO MUNICÍPIO DE NATAL / RN. 2017;14:19-39.

5. Mauss CV, Diecho CA, Bleil C. A gestão de custos como instrumento da eficiência público no Brasil e em outros países. Rev Eletrônica Adm e Tur. 2015;1:595-609.

6. MINISTÉRIO DA SAÚDE. Introdução à Gestão de Custos em Saúde Introdução à Gestão de Custos em Saúde [Internet]. 1a edição. Departamento de Economia da Saúde I e D, editor. Brasília/DF; 2013. Available from: www.saude.gov.br/editora

7. Rocha W. Da contabilidade de custos à gestão estratégica de custos. Rev Contab Finanças [Internet]. 2007;18:7-7. Available from: http://www.scielo.br/scielo.php?script = sci_arttext\&pid = S1519-70772007000100001\&lng = pt\&tlng = pt

8. Fishman P, Hornbrook M. Assigning resources to health care use for health services research: options and consequences. Med Care [Internet]. 2009;47:S70-5. Available from: http://www.pubmedcentral.nih.gov/articlerender.fcgi? artid $=3588569 \&$ tool $=$ pmcentrez\&rendertype $=$ abstract\%5Cnhttp://www.ncbi.nIm.nih.gov/pmc/articles/PMC3588569/

9. Porter M, Kaplan RS. How should we pay for healthcare. Hbr. 2015;

10. Katz M, Franken M, Makdisse M. Value-Based Health Care in Latin America: An Urgent Discussion. J Am Coll Cardiol. 2017;70:904-6.

11. Augustovski F, García Martí S, Pichon-Riviere A. Estándares Consolidados de Reporte de Evaluaciones Económicas Sanitarias: Versión en Español de la Lista de Comprobación CHEERS. Value Heal Reg Issues. 2013;2:338-41.

12. Wilson ECF, Mugford M, Barton G, Shepstone L. Efficient Research Design: Using Value-of-Information Analysis to Estimate the Optimal Mix of Top-down and Bottom-up Costing Approaches in an Economic Evaluation alongside a Clinical Trial. Med Decis Mak. 2016;36:335-48.

13. Conversão de Moedas [Internet]. [cited 2018 Feb 3]. Available from: http://www4.bcb.gov.br/pec/conversao/conversao.asp

14. Robert S. Kaplan and Michael E. Porter. From the Editor Getting to Good How to Solve the Cost Crisis in Health Care. Harv Bus Rev [Internet]. $2011 ; 46-64$. Available from: http://linkinghub.elsevier.com/retrieve/pii/S0140673616325855

15. Elmi M, Hussein H, Nofech-Mozes S, Curpen B, Leahey A, Look Hong N. Budget impact analysis of a breast rapid diagnostic unit. Curr Oncol [Internet]. 2017;24:e214-9. Available from: http://www.current-

oncology.com/index.php/oncology/article/view/3381\%0Ahttp://www.ncbi.nlm.nih.gov/pubmed/28680289\%0Ahttp://www.pubmedcentral.nih.gov/article artid $=$ PMC5486394

16. Inokuchi T, Ikegami N, Gupta V, Rao S, Anderson GF. Comparison of price, volume and composition of services provided to inpatients for two procedures between a US and a Japanese academic hospital. Health (Irvine Calif). 2013;5:703-11.

17. Dormont B, Martins JO, Pelgrin F, Suhrcke M. Health Expenditures, Longevity and Growth. IX Annu Conf Fond Rodolfo deBenedetti Heal Longev Product [Internet]. 2007;1-98. Available from: http://ssrn.com/abstract = 1130315

18. Ferraz MB, Miranda IC, Padovan J, de Soárez PC, Ciconellil R. Health care costs in the last four years of life for private health plan beneficiaries in Brazil. Rev Panam Salud Publica [Internet]. 2008;24:120-6. Available from: http://www.ncbi.nlm.nih.gov/pubmed/19062603

19. Alvaro Koening, Paulo Dorneles Picon, Janaína Feijó, Eliezer Silva GAW. Estimativa do impacto econômico da implantação de um protocolo hospitalar para detecção e tratamento precoce de sepse grave em hospitais púbicos e privados do sul do Brasil. Rev Bras Ter Intensiva. 2010;22:213-9.

\section{Tables}

Table 1: Hospitalization, cost, and demographics data at HMVSC. 
Patient Age (years)

Median [1st; 3rd quartiles]

Minimum; Maximum

Total cost per patient (US\$)

Median [1st; 3rd quartiles]

Minimum; Maximum

Sex

Female

Male

Total Number of Patients

Race

White

Brown

Black

Yellow

Indigenous

Uninformed

Hospital Outcomes

Death

Discharge from hospital

Number of admissions during the period studied

2

3

Length of hospital stay (days)

Median [1st; 3rd quartiles]

Minimum; Maximum

Occupancy rate (\%)
$23.00[1.00-36.00]$

$0.00 ; 98.00$

1,825. 91 [728.22-3,479. 68]

2.36-763,308. 15

$5,849(67.2) *$

$2,853(32.8)$

8,702

$2,844(32.7)$

$2,422(27.8)$

$855(9.8)$

$52(0.6)$

$2(0.0)$

2,527 (29.0)

$236(2.7)$

$8,466(97.3)$

$8,086(92.9)$

$445(5.1)$

$97(1.1)$

$48(0.5)$

$2.95[2.35 ; 4.22]$

$1.00-230.70$

53.49

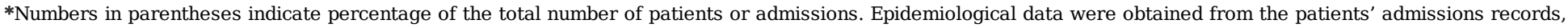

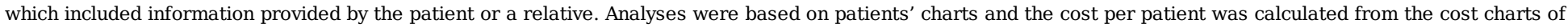
all hospital admissions. Table 2: Average costs per Major Diagnostic Categories 
Alcohol or drug-induced organic and mental conditions

\section{9,358}

Diseases and disorders of musculoskeletal and connective tissues

Diseases *** and disorders of blood, blood forming organs, and immunological disorders

Diseases and disturbances of the circulatory system

Mental disorders and diseases

Non-groupable diseases

Myeloproliferative disorders, poorly differentiated neoplasms

Diseases and disorders of the nervous system

Diseases and disturbances of the hepatobiliary system and pancreas

Diseases and disorders of the respiratory system

Diseases and disorders of the kidneys and urinary tract

Diseases and disorders of the ears, nose, mouth and throat

Injuries, poisonings and toxic drug effects

Endocrine diseases and nutritional and metabolic disorders

Diseases and disturbances of the female reproductive system

Diseases and disturbances of the digestive system

Diseases and disorders of the skin, subcutaneous tissue and breasts

Diseases and disturbances of the male reproductive system

Diseases and disorders of the eyes

Pregnancy, birth and puerperium

Newborn or neonate diseases of perinatal origin
29,532

20,176

19,775

18,192

3

9

73

196

27

32

$15,384 \quad 480$

13,678

12,659

12,553

12,385

11,438

$10,644 \quad 538$

$10,426 \quad 426$

$\begin{array}{ll}9,972 & 57\end{array}$

9,501

8,768

7,161

6,739

$6,513 \quad 88$

4,500

3,389

$2,284 \quad 3,412$

$1,587 \quad 3,072$

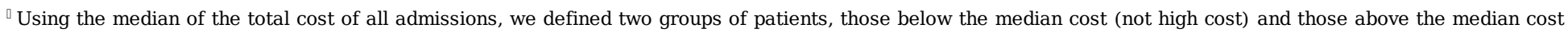

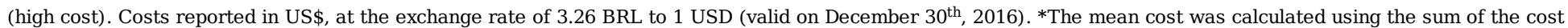

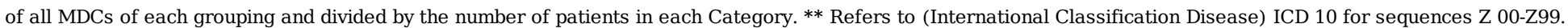
*** Refers to ICD 10 for sequences D50-D99

Table 3 - Relative distribution of the in-patient population relative to higher or lower hospitalization costs. 
HIGHER COST * LOWER COST *

\begin{tabular}{|c|c|c|}
\hline Age (years) & $* * 1.0[1.0-25.0]$ & $36.0(24.0-59.0)$ \\
\hline \multicolumn{3}{|l|}{$\operatorname{Sex} n(\%)^{* * *}$} \\
\hline Female & $3140(65.42 \%)$ & $3156(65.72 \%)$ \\
\hline Male & 1659 (34.56\%) & 1645 (34.26\%) \\
\hline \multicolumn{3}{|l|}{ Race n (\%)*** } \\
\hline White & $14(0.29 \%)$ & $42(0.87 \%)$ \\
\hline Brown & $965(20.10 \%)$ & 2389 (49.75\%) \\
\hline Black & $1(0.02 \%)$ & $3(0.06 \%)$ \\
\hline Yellow & $347(7.23 \%)$ & 607 (12.64\%) \\
\hline \multicolumn{3}{|l|}{ Department $\mathrm{n}(\%)^{* * *}$} \\
\hline Mother-Child & 4419 (92.06\%) & $2148(44.73 \%)$ \\
\hline Surgical Medical Clinic & $246(5.13 \%)$ & 1613 (33.59\%) \\
\hline Transplant & $113(2.35 \%)$ & $851(17.72 \%)$ \\
\hline Oncology & $22(0.46 \%)$ & $190(3.96 \%)$ \\
\hline \multicolumn{3}{|l|}{ Outcome $\mathrm{n}(\%)^{* * *}$} \\
\hline Death & $20(0.42 \%)$ & $216(4.50 \%)$ \\
\hline Live & 4762 (99.21\%) & 4551 (94.77\%) \\
\hline Uninformed & $18(0.38 \%)$ & 35 (0.73\%) \\
\hline Length of hospital stay**** & $2.6[2.3 ; 3.1]$ & $3.9[2.7 ; 8.3]$ \\
\hline \multicolumn{3}{|l|}{ MDC Discharge from hospital n(\%) } \\
\hline Pregnancy, birth and puerperium & 1644 (34.25\%) & $1768(36.82 \%)$ \\
\hline Diseases and disorders of the respiratory system & $106(2.21 \%)$ & $432(9.00 \%)$ \\
\hline Diseases and disorders of the circulatory system & $56(1.17 \%)$ & $424(8.83 \%)$ \\
\hline Diseases and disorders of the digestive system & $49(1.02 \%)$ & $376(7.83 \%)$ \\
\hline Diseases and disorders of the hepatobiliary system and pancreas & $48(1.00 \%)$ & $349(7.27 \%)$ \\
\hline
\end{tabular}

*Total population separated for median cost (in US\$), using Structured Equation Modeling.

** Median age in years.

*** Represented sample and relative frequency.

**** Median and 1st quartile, 3rd quartile, using non-parametric Mann-Whitney tests

Table 4 - Cost drivers distribution

\begin{tabular}{lcc} 
Standard basic Day Care* & $544[431-714]$ & $1,875[789-509]$ \\
Medical exams* & $22[0-61]$ & $208[39-842]$ \\
Material* $^{*}$ & $14[8-38]$ & $135[58-407]$ \\
Medications* & $0[0-17]$ & $74[31-298]$ \\
Operating room* & $0[0-0]$ & $867[0-1428]$ \\
\hline
\end{tabular}

* Structured Equation Modeling was used to identify median [1st quartile, 3rd quartile] and the distribution of cost drivers (cost drivers are the structural determinants of the cost of an activity) among the sample of high versus not high cost hospitalizations, in US\$. 


\section{Abbreviations}

WHO - World Health Organization, DC - cost drivers, DRG - Diagnosis Related Group, DW - Data Warehouse, HIAE - Hospital Israelita Albert Einstein, MD -

Medical Doctor, MDC - Major Diagnostic Categories, Programa de Apoio Institucional ao SUS - Institutional Support Program to the Unified Health System, RN

- Registered Nurse 